\title{
Research on the Risk Evaluation Model and Application of Coal Logistics Supply Chain Network
}

\author{
Lieying Zhao, Xifu Wang, Hongsheng Sun \\ Department of Traffic and Transportation, Beijing Jiaotong University, Beijing, 100044, China
}

\begin{abstract}
This paper identifies the risk factors of coal logistics supply chain network, and it has established 15 qualitative and quantitative risk evaluation index systems of coal logistics supply chain network. At the same time, it uses genetic algorithm to optimize the weight and threshold of BP neural network, and it establishes the model and algorithm of risk evaluation based on genetic neural network. Finally, it takes an enterprise in Shanxi as an example, it uses the model of risk evaluation of genetic neural network established by MATLAB software to train the sample data of examples, and through the comparison and analysis of results, it verifies the feasibility of risk assessment of coal logistics supply chain network model based on Genetic Neural Network.
\end{abstract}

Keywords-coal logistics supply chain network, risk assessment, genetic neural network.

\section{INTRODUCTION}

The imbalance problem of China's current coal supply and demand is very prominent. Various uncertain factors have great influence on the risk of supply chain network of coal logistics. In order to promote the healthy development of coal industry and improve the supply efficiency of coal logistics, it is important theoretical and practical significance to the study of risk analysis and evaluation of coal supply chain logistics network.

\section{The Establishment OF A Risk Assessment ModeL BASED ON THE GENETIC NEURAL NETWORK}

Through the research of BP neural network and genetic algorithm, this paper uses genetic algorithm to optimize the weight and threshold of BP neural network, it gained mathematics model of supply chain risk evaluation of coal logistics network based on genetic neural network.

1) Determine the target function

Risk assessment model based on the BP neural network is actually looking for appropriate weights and threshold, it makes comprehensive evaluation on the known targets through transfer function. Therefore, it uses vector $\mathrm{X}$ to represent the connection weights of each neuron between neurons in the neural network and the neuron threshold, and $\mathrm{X}$ is called weight -threshold vector of the network, the $\mathrm{X}$ can be expressed as:

$$
\left\{\begin{array}{l}
X=\left\{x_{1}, x_{2}, \ldots, x_{N_{1}}\right\}^{T}=\left\{w_{1}, w_{2}, \ldots, w_{N_{2}}, \theta_{1}, \theta_{2}, \ldots, \theta_{N_{3}}\right\} \\
N_{1}=M * S+S * N \\
N_{2}=M+S \\
N_{3}=N_{1}+N_{2}=M * S+S * N+M+S
\end{array}\right.
$$

Among them, $w_{i}$ : input layer to the hidden layer weights.

$\theta_{i}$ : the individual fitness evaluation function

$M$ :the number of input layer nodes:

$S$ :the number of hidden layer nodes:

$N$ :the number of output layer nodes:

$N_{3}$ :weight: the threshold vector dimension

2) The sub model of genetic algorithm (GAM)

The sub model of genetic algorithm can be expressed as:

$$
G A M=(C, E, P, M, \Phi, \Gamma, \Psi, T)
$$

Among them, $C$ :the coding method of the individual

$E$ : the individual fitness evaluation function

$P$ : the initial population

$M$ : the population size:

$\Phi$ : selection operator

$\Gamma$ : crossover operator

$\Psi$ : mutation operator

3) The fitness function

In BP network, the error function is:

$$
E=\frac{1}{2} \sum_{k-1}^{p}\left(d_{k}^{p}-o_{k}^{p}\right)^{2}
$$

Among them, $P$ :the total number of samples

$$
\begin{aligned}
& O_{k} \text { :the output vectors of the output layer } \\
& d_{k} \text { :the desired output vector }
\end{aligned}
$$

In this model, genetic algorithm is the role of finding a set of weights and a closed value vector to minimize the error, therefore, the objective function in genetic algorithm is:

$$
E \min =\frac{1}{2} \sum_{k-1}^{p}\left(d_{k}^{p}-o_{k}^{p}\right)^{2}
$$

Therefore, the fitness function $\mathrm{F}$ is: 


$$
F=\frac{1}{E}
$$

In general, the risk assessment model of coal logistics supply chain network based on the genetic neural network are as following.

$$
\left\{\begin{array}{l}
G A M=(C, E, P, M, \Phi, \Gamma, \Psi, T) \\
X=\left\{x_{1}, X_{2}, \ldots, X_{N_{1}}\right\}^{T}=\left\{w_{1}, w_{2}, \ldots, w_{N_{2}}, \theta_{1}, \theta_{2}, \ldots, \theta_{N_{3}}\right\} \\
E=\frac{1}{2} \sum_{k-1}^{p}\left(d_{k}^{p}-o_{k}^{p}\right)^{2} \\
F=\frac{1}{E} \\
N_{1}=M * S+S * N \\
N_{2}=M+S \\
N_{3}=N_{1}+N_{2}=M * S+S * N+M+S
\end{array}\right.
$$

\section{IIITHE EXAMPLE ANALYSIS}

\section{A. The establishment of risk evaluation system}

This paper takes the coal supply chain logistics network of a coal enterprise in Shanxi as the research object, and it measures the risks of this research object to verify whether the risk evaluation based on genetic neural network is reasonable and efficient. The risk evaluation index value of coal supply chain logistics network of Jincheng branch is shown in table 3-1.

TABLE 3-1. THE RISK EVALUATION INDEX VALUE OF COAL SUPPLY CHAIN LOGISTICS NETWORK OF JINCHENG BRANCH

\begin{tabular}{|c|c|c|c|c|c|}
\hline $\begin{array}{c}\text { The risk } \\
\text { evaluation } \\
\text { index }\end{array}$ & $\begin{array}{c}\text { Index } \\
\text { value }\end{array}$ & $\begin{array}{c}\text { The risk } \\
\text { evaluation } \\
\text { index }\end{array}$ & $\begin{array}{c}\text { Index } \\
\text { value }\end{array}$ & $\begin{array}{c}\text { The risk } \\
\text { evaluation } \\
\text { index }\end{array}$ & $\begin{array}{c}\text { Index } \\
\text { value }\end{array}$ \\
\hline $\begin{array}{c}\text { The } \\
\text { vulnerability } \\
\text { of structure } \\
\text { network }\end{array}$ & 0.39 & $\begin{array}{c}\text { The degree of } \\
\text { information } \\
\text { integration }\end{array}$ & 0.35 & $\begin{array}{c}\text { The accident } \\
\text { rate of } \\
\text { transportation }\end{array}$ & 0.45 \\
\hline $\begin{array}{c}\text { Mutual } \\
\text { cooperation } \\
\text { among } \\
\text { enterprises }\end{array}$ & 0.60 & $\begin{array}{c}\text { Supplier } \\
\text { selection }\end{array}$ & 0.20 & $\begin{array}{c}\text { The } \\
\text { efficiency of } \\
\text { logistics } \\
\text { nodes }\end{array}$ & 0.53 \\
\hline $\begin{array}{c}\text { The } \\
\text { manager's } \\
\text { business } \\
\text { decision }\end{array}$ & 0.72 & $\begin{array}{c}\text { The coal } \\
\text { quality }\end{array}$ & 0.44 & $\begin{array}{c}\text { Government } \\
\text { regulation } \\
\text { and control } \\
\text { policy }\end{array}$ & 0.28 \\
\hline $\begin{array}{c}\text { The } \\
\text { effectiveness } \\
\text { of } \\
\text { information }\end{array}$ & 0.54 & $\begin{array}{c}\text { The } \\
\text { completion } \\
\text { rate of } \\
\text { production } \\
\text { plan }\end{array}$ & 0.36 & $\begin{array}{c}\text { The changes } \\
\text { of economic } \\
\text { environment }\end{array}$ & 0.54 \\
\hline $\begin{array}{c}\text { Information } \\
\text { symmetry }\end{array}$ & 0.59 & $\begin{array}{c}\text { Market } \\
\text { demand } \\
\text { forecasting }\end{array}$ & 0.60 & $\begin{array}{c}\text { Natural } \\
\text { disaster }\end{array}$ & 0.12 \\
\hline
\end{tabular}

In this paper, by using the risk evaluation model based on genetic neural network, it solves the above index value to get the risk evaluation value of the coal supply chain logistics network, and it uses the risk evaluation set defining the risk value. Finally, it determines the supply chain risk level of coal logistics network of Jincheng branch.

\section{B. The risk evaluation of genetic neural network of coal} logistics supply chain network.

- Construct training samples.

For the risk evaluation of coal logistics supply chain network, it is necessary to choose the coal logistics supply chain network divided by the area, to construct training samples with the core of the coal enterprise in the network as a unit, and this paper mainly adopts the expert scoring method to construct training samples, it calculated the comprehensive score of the risk of each index of coal supply chain logistics network, as a genetic neural network learning samples. According to the actual situation, this paper obtains the desired output of coal supply chain logistics network. Then, according to these datas, it uses BP neural network training samples.

- BP network topology structure

The rationality of BP network topology structure directly affects the objectivity, accuracy and adaptability of the results of risk evaluation model of coal supply chain logistics network.

1) The number of input nodes

According to the 15 risk evaluation indexes of coal supply chain logistics network, each index respectively corresponds to the neurons of the neural network input layer, So the number of neurons in input layer of neural network is 15.

2) The number of output nodes

Because the requirements of this paper is to determine the final risk situation of coal logistics supply chain network, the final output of the model is the integrated risk value of the model. So, the number of nodes of output layer is one.

3)The setting of training parameters

According to the size of the training sample, the cycle times of learning epochs is set to 2000, the selection of learning rate $\mathrm{lr}$ is set to 0.1 , the biggest training error mse is $10^{-4}$. Activation function in the role of hidden layer is a nonlinear function of tansig (s type tangent) function, activation function in the role of output layer is a nonlinear function of purelin (s type tangent) function, the training function uses the traincgf function.

4) Determine the hidden layer nodes.

The number of neurons in hidden layer is obtained by the empirical formula $S=\sqrt{M+N}+\gamma$. Among them, $\mathrm{M}$ and $\mathrm{N}$ respectively stand for the number of the input and output layer nodes, $\gamma$ constantly gets the number between 1 to 10 . After calculation, it can determine the scope of the number of hidden layer neurons is between 5 and 14. In order to determine the best number of hidden layer neurons, performance comparison and analysis are made by BP network topology structure of the above. Through the results of comparison analysis, considering the network convergence rate and mean square error, when the number of nodes in the hidden layer is 8 , mean square error is 
relatively small, and the number of training is still relatively reasonable. It can be concluded that BP network topology structure finally is $15-8-1$.

- Genetic algorithm optimizes the weight and threshold of BP network.

It can be seen from the model of risk assessment of coal logistics supply chain network based on genetic neural network that the first thing is to optimize the weights and thresholds of the BP neural network, and the optimization for them is to be performed at the same time. By using the MATLAB software, taking constructed training samples as the input of the network, this paper uses genetic algorithm to optimize the weights and thresholds of the BP neural network model that has been established. According to the fitness function, it selects an optimal individual as the initial weights and threshold of the BP neural network, to achieve the optimization of the BP neural network model.

- BP network training process and results

By genetic operations, this paper selects the optimal individual fitness, the decoding values in the chromosome are assigned to established BP neural network as the initial weight and threshold of the network, then it uses BP neural network training. It is based on the global optimization of genetic algorithm to trimming the weight and threshold of $\mathrm{BP}$ neural network, then it calculates the optimal distribution of the weight and threshold of BP neural network. The training output results are shown in table 3-2 and figure 3-1the mean variance curve of the BP neural network optimized by GA.

TABLE 3-2. TRAINING OUTPUT RESULTS

\begin{tabular}{|c|c|c|c|c|c|c|c|}
\hline $\begin{array}{c}\text { Serial } \\
\text { numb } \\
\text { er }\end{array}$ & 1 & 2 & 3 & 4 & 5 & 6 & 7 \\
\hline $\begin{array}{l}\text { The } \\
\text { output } \\
\text { results }\end{array}$ & $\begin{array}{c}0.605 \\
2\end{array}$ & $\begin{array}{c}0.365 \\
0\end{array}$ & $\begin{array}{c}0.375 \\
4\end{array}$ & $\begin{array}{c}0.398 \\
6\end{array}$ & $\begin{array}{c}0.274 \\
1\end{array}$ & $\begin{array}{c}0.452 \\
5\end{array}$ & $\begin{array}{c}0.411 \\
6\end{array}$ \\
\hline $\begin{array}{c}\text { Serial } \\
\text { numb } \\
\text { er }\end{array}$ & 8 & 9 & 10 & 11 & 12 & 13 & 14 \\
\hline $\begin{array}{l}\text { The } \\
\text { output } \\
\text { results }\end{array}$ & $\begin{array}{c}0.363 \\
4\end{array}$ & $\begin{array}{c}0.233 \\
9\end{array}$ & $\begin{array}{c}0.554 \\
7\end{array}$ & $\begin{array}{c}0.482 \\
5\end{array}$ & $\begin{array}{c}0.335 \\
7\end{array}$ & $\begin{array}{c}0.221 \\
0\end{array}$ & $\begin{array}{c}0.365 \\
0\end{array}$ \\
\hline $\begin{array}{l}\text { Serial } \\
\text { numb } \\
\text { er }\end{array}$ & 15 & 16 & 17 & 18 & 19 & 20 & 21 \\
\hline $\begin{array}{l}\text { The } \\
\text { output } \\
\text { results }\end{array}$ & $\begin{array}{c}0.307 \\
8\end{array}$ & $\begin{array}{c}0.433 \\
9\end{array}$ & $\begin{array}{c}0.505 \\
5\end{array}$ & $\begin{array}{c}0.325 \\
7\end{array}$ & $\begin{array}{c}0.586 \\
2\end{array}$ & $\begin{array}{c}0.411 \\
6\end{array}$ & $\begin{array}{c}0.254 \\
7\end{array}$ \\
\hline
\end{tabular}

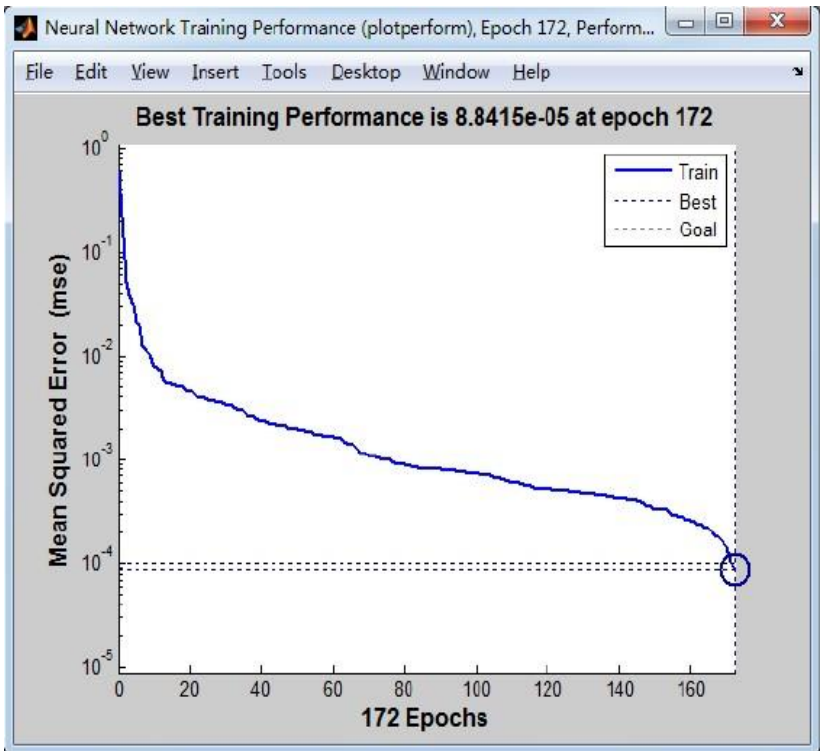

Figure 3-1. The mean variance curve of the BP neural network optimized by GA.

It is compared with the training results of the single BP neural network evaluation method. The comparison results are shown in table 3-3 the comparison table of the genetic neural network model and the BP neural model.

TABLE 3-3. THE COMPARISON TABLE OF THE GENETIC NEURAL NETWORK MODEL AND THE BP NEURAL MODEL

\begin{tabular}{|l|l|l|}
\hline $\begin{array}{l}\text { The risk } \\
\text { evaluation model }\end{array}$ & $\begin{array}{l}\text { Number } \\
\text { of cycles }\end{array}$ & $\begin{array}{l}\text { Mean square error } \\
\text { (MSE) }\end{array}$ \\
\hline BP neural network & 252 & 0.000098143 \\
\hline $\begin{array}{l}\text { Genetic neural } \\
\text { network }\end{array}$ & 172 & 0.000088415 \\
\hline
\end{tabular}

From the above comparison analysis, the traditional risk evaluating model of BP neural network iterative cycle 252, and the mean square error is 0.000098143 . However, the risk assessment model of BP neural network optimized by genetic algorithm iterative cycle 172 times can make mean square errors be 0.000088415. Therefore, weight and threshold of BP neural network optimized by genetic algorithm can well improve the convergence speed of the algorithm of BP neural network, it solves the problem of slow convergence speed and easy to cause the local minimum, making the training more accuracy.

\section{The results of risk assessment example}

This paper uses BP neural network that has been trained, according to the risk evaluation index value of the coal logistics supply chain network of Jincheng branch,

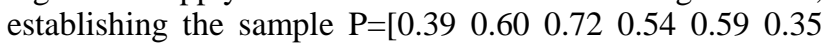
0.200 .440 .360 .600 .450 .530 .280 .540 .12 ], to carry on the appraisal to the risk status of the coal supply chain logistics network of Jincheng branch, it obtains the risk assessment result of 0.558 , in the interval of the evaluation set $[0.5$, 
0.67], that is, the risk status of the coal logistics supply chain network of Jincheng branch is in general to more dangerous interval. This shows that a certain risk of the coal logistics supply chain network still exists, it need to identify the related factors of risk, and strengthen the management to reduce the risk.

TABLE 3-4. RISK INTEGRATION VALUE COMPARISON TABLE

\begin{tabular}{|c|c|}
\hline $\begin{array}{c}\text { The comprehensive value of risk } \\
\text { assessment by expert control standard }\end{array}$ & 0.55 \\
\hline $\begin{array}{c}\text { The value of the risk evaluation of the } \\
\text { genetic neural network model }\end{array}$ & 0.558 \\
\hline
\end{tabular}

From the above result, the genetic neural network risk assessment model established in this paper has certain feasibility and accuracy, can be used for the risk assessment of the coal supply chain logistics network.

\section{The RESEARCH CONCLUSION}

In this paper, the risk assessment of genetic neural network is used in coal supply chain logistics network, the model and algorithm of risk evaluation based on genetic neural network is established, and taking an enterprise in Shanxi as an example, the analysis of the model is verified, and ideal effect is achieved.

\section{REFERENCES}

[1] Yingjie Lei, Shanwen Zhang, Xuwu Li, Chuangming Zhou. MATLAB genetic algorithm toolbox and its application [M]. Xi'an Electronic Science Technology Major Science Press, 2005

[2] Zhen Yang. Risk assessment analysis and applications based on genetic neural network of railway dangerous goods transportation [D]. Beijing: Beijing Jiaotong University, 2011

[3] Tianzhu Liu. Auto parts suppliers evaluation algorithm applications and study [D]. Wuhan: Wuhan University of Technology, 2006

[4] ChanghaSun i. The risk assessment and management research of China's construction enterprises in the supply chain [D]. Liaoning: Dalian Maritime University, 2009 